\title{
Advanced Characterization Techniques in High- Temperature Oxidation and Corrosion Studies
}

\author{
Yves Wouters • Bruce Pint • Daniel Monceau
}

Published online: 18 December 2012

(C) Springer Science+Business Media New York 2012

Recent improvements in characterization techniques have greatly advanced fundamental understanding of the complex processes associated with high temperature oxidation and corrosion. These techniques allow for chemical and structural analyses at high resolutions, now clearly in the micrometer range, but also submicron for some and even down to the atomic scale with such techniques as atom probe and aberration corrected electron microscopy. Added to these is the possibility to conduct advanced analyses in situ. In this present issue, it will be clearly demonstrated that substrate and oxide scale microstructures, playing a key role in a number of systems, can now be characterized with exquisite detail and often in three-dimensions, such as by the coupling of FIB, MEB/FEG and even EBSD. In addition, residual stress mapping by Raman spectroscopy, the study of semiconductor properties with photoelectrochemistry techniques, and isotopic tracer experiments in conjunction with SIMS analysis to identify principal reacting and transport processes, all provide excellent examples of what are available to better understand the mechanisms involved in oxide-scale formation at elevated temperatures.

\footnotetext{
Y. Wouters ( $₫)$

Science et Ingénierie des Matériaux et Procédés (SIMaP), University of Grenoble, 1130 de la Piscine, BP 75, 38402 Saint-Martin-d'Hères Cedex, France

e-mail: Yves.Wouters@simap.grenoble-inp.fr

B. Pint

Materials Science and Technology Division, Oak Ridge National Laboratory, Oak Ridge,

TN 37831-6156, USA

e-mail: pintba@ornl.gov

D. Monceau

INP Toulouse-CNRS CIRIMAT, 31030 Toulouse, France

e-mail: daniel.monceau@ensiacet.fr
} 
The following key papers stem from presentations that were given at the 8th international conference on High Temperature Corrosion and Protection of Materials (HTCPM2012), which was held at Les Embiez Island, France, on the 20-25th of May 2012. 